\title{
Polyunsaturated fatty acids and inflammation
}

Oléagineux, Corps Gras, Lipides. Volume 11, Numéro 1, 38-45, JANVIER/FÉVRIER 2004, Acides gras oméga 3 : aspects métaboliques

Auteur(s) : Philip C. CALDER

Institute of Human Nutrition, School of Medicine, University of Southampton, Bassett Crescent East, Southampton SO16 7PX, United Kingdom. Telephone : 44-(0)23 80594223

Fax : 44-(0)23 80595489

E-mail : pcc@soton.ac.uk

Summary : The $\mathrm{n}-6$ polyunsaturated fatty acid arachidonic acid gives rise to the eicosanoid family of inflammatory mediators (prostaglandins, leukotrienes and related metabolites) and through these regulates the activities of inflammatory cells, the production of cytokines and the various balances within the immune system. Fish oil and oily fish are good sources of long chain n-3 polyunsaturated fatty acids. Consumption of these fatty acids decreases the amount of arachidonic acid in cell membranes and so available for eicosanoid production. Thus, n-3 polyunsaturated fatty acids act as arachidonic acid antagonists. Components of both natural and acquired immunity, including the production of key inflammatory cytokines, can be affected by $n-3$ polyunsaturated fatty acids. Although some of the effects of $n-3$ fatty acids may be brought about by modulation of the amount and types of eicosanoids made, it is possible that these fatty acids might elicit some of their effects by eicosanoid-independent mechanisms. Such $n-3$ fatty acid-induced effects may be of use as a therapy for acute and chronic inflammation, and for disorders that involve an inappropriatelyactivated immune response.

Keywords : arachidonic acid, eicosapentaenoic acid, polyunsaturated fatty acid, fish oil, inflammation, immune function, cytokine, eicosanoid, prostaglandin, leukotriene, monocyte, macrophage

\section{ARTICLE}

The immune system in health and disease - a general overview

The immune system acts to protect the host from infectious agents that exist in the environment (bacteria, viruses, fungi, parasites). It serves to distinguish "non-self" from "self". In addition the immune system plays an important role in the identification and elimination of tumour cells. Thus, an effective and efficient immune system is central to host defence against infectious diseases and cancer. A detailed description of the components of the immune system, how they work and how they interact may be found in standard immunology textbooks [e.g. 1]. Suffice it to say that the immune system responds to challenge (e.g. a bacterial infection) with an increase in the activity of certain components that act to eliminate the source of the challenge. This response will include both non-specific and specific actions that will involve a variety of cell types, mediators and chemical 
agents. The exact nature of the response will depend upon the origin and nature of the antigen (and so the origin and nature of the challenge). However, inflammation forms part of the normal innate immune response to challenge. The immune response, particularly its inflammatory component, is, by definition, highly destructive and therefore it must be regulated in order that it does not proceed for a longer duration than is required and that it does not cause excessive damage to host tissues. Whilst the capacity to mount a vigorous immune response is central to effective host defence against the range of possible infectious organisms, a number of human diseases are associated with inappropriate activation or activity of the immune response. It is likely that the combination of genetic predisposition and certain environmental and/or lifestyle factors allows the disease to manifest itself, the end result being damage to host tissues. Frequently these diseases involve activation of inflammatory cells and excessive or inappropriate production of inflammatory mediators [1]. Hence they are termed inflammatory diseases. Examples of inflammatory diseases include rheumatoid arthritis, allergic diseases, and inflammatory bowel diseases. It is now recognised that atherosclerosis is also an inflammatory disease [2]. Furthermore, acute cardiovascular events are driven by inflammatory activities within the vessel wall [3]. Among the mediators often involved in inflammatory disease are the eicosanoids and the pro-inflammatory cytokines. The latter include tumour necrosis factor (TNF)- $\alpha$, interleukin (IL) -1 and IL-6. In excess, inflammatory mediators are involved in causing a range of local and systemic responses that can be detrimental to the host.

\section{The fatty acid composition of inflammatory cells can be modulated by dietary fatty acids}

Human inflammatory and immune cells tend to rather rich in arachidonic acid, although there is some variation in their fatty acid composition, which may reflect, in part, variation in the dietary intake of various fatty acids [4]. Typically, the $n-6$ polyunsaturated fatty acid (PUFA) arachidonic acid comprises about 15 to $25 \%$ of total fatty acids present in human inflammatory and immune cells. In contrast, the n-3 PUFA eicosapentaenoic acid (EPA) is a fairly minor constituent comprising an average of $<1 \%$ of total fatty acids. However, this can be altered by increased dietary intake of $n$ 3 PUFA. For example, supplementing the diet of human volunteers with fish oil in capsules (rich in n3 PUFA) results in incorporation of both EPA and docosahexaenoic acid (DHA) into blood neutrophils [5-9], monocytes [5, 7, 10], $T$ and B lymphocytes [7], and mononuclear cells [11-15]. This incorporation is largely at the expense of arachidonic acid. Both EPA and DHA are readily taken up, with near-maximal incorporation occurring within 4 weeks $[14,15]$. Incorporation of both fatty acids occurs in a dose response manner [9]. Once dietary supplementation ceases, EPA is lost from the cells within 8 weeks, but DHA is better retained [14]. Increased intake of the shorter chain n-3 PUFA, $\alpha$-linolenic acid, also results in increased content of EPA in human inflammatory and immune cells, provided that sufficient $\alpha$-linolenic acid is consumed [9, 13, 15-18].

\section{Eicosanoids provide a link between the fatty acid composition of cells and inflammation}

The principal functional role for arachidonic acid in inflammatory cells is as a substrate for synthesis of the eicosanoid family of bioactive mediators. These include the prostaglandins (PG), thromboxanes, leukotrienes (LT), hydroxy and hydroperoxy eicosatetraenoic acids and lipoxins. Arachidonic acid in cell membranes can be mobilised by various phospholipase enzymes, especially phospholipase $A_{2}$, and the free arachidonic acid can subsequently act as a substrate for the enzymes that synthesise eicosanoids (figure 1). Metabolism by cyclooxygenase enzymes (COX) gives rise to the 2-series prostaglandins and thromboxanes (figure 1). There are two isoforms of COX: COX-1 is a 
constitutive enzyme and COX-2 is induced in inflammatory cells as a result of stimulation and is responsible for the markedly elevated production of prostaglandins that occurs upon cellular activation. Prostaglandins are formed in a cell-specific manner. For example, upon activation monocytes and macrophages produce large amounts of $\mathrm{PGE}_{2}$ and $\mathrm{PGF}_{2 \alpha}$, neutrophils produce moderate amounts of $\mathrm{PGE}_{2}$, and mast cells produce $\mathrm{PGD}_{2}$. Lymphocytes are a poor source of prostaglandins, but may release arachidonic acid extracellularly for use by other cell types [19]. Metabolism of arachidonic acid by the 5-lipoxygenase (5-LOX) pathway gives rise to hydroxy and hydroperoxy derivatives, and the 4-series leukotrienes, $\mathrm{LTA}_{4}, \mathrm{~B}_{4}, \mathrm{C}_{4}, \mathrm{D}_{4}$ and $\mathrm{E}_{4}$ (figure 1). 5-LOX is found in mast cells, monocytes, macrophages, granulocytes and lymphocytes. Arachidonic acid-derived eicosanoids are involved in modulating the intensity and duration of inflammatory responses and in regulating immune responses [see 20, 21 for reviews]. Both $\mathrm{LTB}_{4}$ and $\mathrm{PGE}_{2}$ have a number of pro-inflammatory effects (table 1). Note however, that $\mathrm{PGE}_{2}$ also acts to down-regulates the production of the classic inflammatory cytokines (TNF, IL-1 and IL-6) and inhibits the production of 4-series LT (table 1). PGE 2 also induces the production of lipoxins [22], which are now recognised to be inflammation "stop" signals $[23,24]$. Thus, $\mathrm{PGE}_{2}$ is both a mediator and a regulator of inflammation, and exerts both pro- and anti-inflammatory actions. $\mathrm{PGE}_{2}$ also promotes immunoglobulin $E$ production by $B$ lymphocytes and so in this respect $P \mathrm{PE}_{2}$ is pro-allergic. Finally, $\mathrm{PGE}_{2}$ inhibits $T$ cell proliferation and the production of the Th1-type cytokine interferon- $\gamma$. In these respects $\mathrm{PGE}_{2}$ is immunosuppressive.

Table 1. Some effects of $P G E_{2}$ and $L T B_{4}$ on inflammation and immunity.

\begin{tabular}{|l|l|l|}
\hline PGE & LTB $_{4}$ \\
\hline Induces fever & Pro-inflammation : \\
\hline Increases vascular permeability & Increases vascular permeability \\
\hline Increases vasodilatation & Chnemonces local blood flow \\
\hline Causes pain & Induces release of lysosomal enzymes \\
\hline Enhances pain caused by other agents & Induces release of reactive oxygen species by granulocytes \\
\hline Anti-inflammation : & Increases production of TNF, IL-1 and IL-6 \\
\hline Inhibits production of TNF, IL-1 and IL-6 & \\
\hline Inhibits 5-LOX & \\
\hline
\end{tabular}




\begin{tabular}{|l|l|l|}
\hline Immunosuppression : & \\
\hline Induces lipoxin production & & \\
\hline Inhibits production of IL-2 and IFN-Y & \\
\hline Inhibits lymphocyte proliferation & \\
\hline Pro-allergy : & \\
\hline Promotes immunoglobulin E production & \\
\hline
\end{tabular}

Since significantly increased consumption of long chain n-3 PUFA results in a decrease in the amount of arachidonic acid in the membranes of inflammatory cells, there will be less substrate available for synthesis of eicosanoids from arachidonic acid. In accordance with this, fish oil feeding results in a decreased capacity of inflammatory cells to synthesise COX- and 5-LOX-derived eicosanoids from arachidonic acid [e.g. 5, 6, 11, 13, 25]. However, the effects of n-3 PUFA on eicosanoid production extend beyond simply decreasing the amount of substrate available. For example, EPA competitively inhibits the oxygenation of arachidonic acid by COX [26]. Cell culture studies have demonstrated that $n-3$ PUFA suppress cytokine-induction of the COX-2 and 5-LOX genes [27, 28]. It is the net result of these various actions that accounts for the decreased generation of arachidonic-acid derived eicosanoids by $n-3$ PUFA. The reduction in generation of arachidonic acid-derived mediators that accompanies fish oil consumption has lead to the idea that fish oil is anti-inflammatory. In addition to inhibiting metabolism of arachidonic acid, EPA is able to act as a substrate for both COX and 5-LOX (figure 1), giving rise to derivatives which have a different structure to those produced from arachidonic acid (i.e. 3-series PG and 5-series LT). Thus, the EPA-induced suppression in the production of arachidonic acid-derived eicosanoids may be accompanied by an elevation in the production of EPA-derived eicosanoids. This is most evident for the 5-LOX products of EPA metabolism $[5,6]$. The eicosanoids produced from EPA are considered to be less biologically potent than the analogues synthesised from arachidonic acid, although the full range of biological activities of these compounds has not been investigated. Therefore, it possible that EPA gives rise to eicosanoids that are less inflammatory, less pro-allergic and less immunosuppressive than those produced from arachidonic acid [see 29, 30 for further discussion]. Interestingly recent studies have revealed that n-3 PUFA give rise to novel anti-inflammatory eicosanoids generated via COX-2 [31].

\section{Modulating inflammation with dietary $n-3$ fatty acids}

There is a large literature based upon cell culture and animal feeding studies investigating the effects of n-3 PUFA on inflammation (and immune function). These studies have established a basis for effects that might be observed following manipulation of the fatty acid composition of the human diet and have been very useful in identifying mechanisms of action of n-3 PUFA. A description of these studies is beyond the scope of this review, which will focus upon results from human studies. However, a number of review articles serve to summarise, evaluate and discuss these studies [3237]. 
Studies investigating the effect of fish oil on human inflammatory and immune cell functions and responses date back to the early 1980s and there is a large literature in this area [reviewed in 38]. Effects on a number of cellular functions and on a range of mediators have been investigated. Most studies have used fish oil, which contains both EPA and DHA.

\section{Chemotaxis, Respiratory burst and Adhesion}

Fish oil, providing between 2.3 and $14.5 \mathrm{~g}$ EPA plus DHA/day has been reported to decrease neutrophil chemotaxis $[5,6,39-41]$, neutrophil respiratory burst $[8,42,43]$, and neutrophil binding to endothelial cells [5]. Fish oil, providing 4.5 to $5.3 \mathrm{~g}$ EPA plus DHA/day, decreased monocyte chemotaxis [11, 39, 40] and respiratory burst [10]. However, lower doses of long chain n-3 PUFA ( 0.55 to $2.3 \mathrm{~g} /$ day) did not affect neutrophil or monocyte respiratory burst $[9,18,44,45]$ or neutrophil chemotaxis [9]. Although Hughes et al. [46] reported that $1.6 \mathrm{~g}$ EPA plus DHA/day for 3 weeks decreased intercellular adhesion molecule 1 (ICAM-1) on the surface of blood monocytes, this effect was not confirmed in a recent study using 0.77 and $1.7 \mathrm{~g}$ EPA plus DHA/day for 6 months [18].

\section{Monocyte-derived inflammatory cytokines}

Fish oil providing $>2.4 \mathrm{~g}$ EPA plus DHA/day decreased the production of TNF $[11,13,25]$, IL-1 [11, 13, 25] and IL-6 [25] by mononuclear cells. Another study, providing subjects consuming a low-fat diet that included oily fish (daily intake of $1.2 \mathrm{~g}$ EPA plus DHA), reported decreased production of TNF, IL1 and IL-6 [47]. Intake of $4.55 \mathrm{~g}$ EPA plus DHA as ethyl esters/day for 4 weeks significantly decreased platelet-derived growth factor (PDGF)-A and $-B$ and monocyte chemotactic peptide-1 mRNA in monocytes [48]. This is consistent with the significant decrease in plasma PDGF concentration observed in women consuming $4 \mathrm{~g}$ fish oil/day (1.2 g EPA plus DHA/day) for 4 weeks [49]. In contrast to the above studies are a number reporting no effect of 0.55 to $3.4 \mathrm{~g}$ EPA plus DHA/day on production of TNF $[12,14,18,44,45,50-52]$, IL-1 [12, 14, 18, 44, 45, 50-53] and IL-6 [14, 18, 45, 50]. Possible reasons for the discrepancies in the literature are discussed in detail elsewhere [38], but may relate to the dose of n-3 PUFA used, the duration of the study, the age of the subjects studied, sample size, and differences in background diet. Duration appears not to be a factor because some relatively short studies report effects [e.g. 13], whereas other short [50] and longer term [18, 51] studies report no effect. However, the dose of long chain n-3 PUFA provided is likely to be important : a recent study reported for the first time a dose-response relationship between EPA plus DHA and IL-6 production [52]. This study reported that the threshold for an effect of long chain n3 PUFA on IL- 6 production is between 0.44 and $0.94 \mathrm{~g} /$ day. However, dose cannot be the sole explanation for differences in the literature, because some studies providing as much as $3.2 \mathrm{~g}$ EPA plus DHA per day report no effect on cytokine production [e.g. 14]. Another recent study has highlighted a further possible explanation. This study reports that polymorphisms in the promoter regions of the TNF- $\alpha$ and TNF- $\beta$ genes play a role in conferring sensitivity of TNF- $\alpha$ production to fish oil intervention [53].

\section{Soluble adhesion molecules}

The concentrations of soluble ICAM-1 (sICAM-1), soluble vascular cell adhesion molecule 1 (sVCAM1) and soluble E-selectin (E-selectin) were significantly negatively correlated with the concentration of non-etherified EPA in the bloodstream of elderly males at high risk of coronary heart disease [54]. 
Furthermore the concentrations of SICAM-1 and SVCAM-1 were significantly negatively correlated with the concentration of non-esterified DHA in the bloodstream [54]. These observations suggest that an increase in long chain n-3 PUFA may decrease endothelial inflammation, as indicated by soluble adhesion molecule concentrations. In accordance with this, consumption of $1.1 \mathrm{~g}$ EPA plus DHA/day for 12 weeks by subjects aged 55 to 75 years significantly decreased sVCAM1 concentration, with non-significant decreases in sICAM-1 and SE-selectin concentrations [45]. Average decreases were $26 \%$ (sVCAM-1), $14 \%$ (sICAM-1) and $23 \%$ (sE-selectin). A reduction in soluble adhesion molecule concentrations was not observed in young male subjects consuming $1.2 \mathrm{~g}$ EPA plus DHA/day for 12 weeks [55], suggesting that older subjects may be more sensitive to the effects of long chain n-3 PUFA. In contrast to the observation of Thies et al. [45], three studies report increases in these soluble adhesion molecules following fish oil administration [56-58]. However, these studies used high doses of fish oil providing 3.3 to $5.1 \mathrm{~g}$ EPA plus DHA/day, studied subjects with much higher cardiovascular risk and used different study designs from that used by Thies et al. [45] [see 55 for a discussion].

\section{C-reactive protein}

C-reactive protein (CRP) is an acute phase protein synthesised by the liver in response to infections and to certain inflammatory stimuli, most notably IL-6. Thus, plasma CRP concentrations are elevated in chronic inflammatory conditions and in individuals who are obese or with advanced cardiovascular disease. Since $n-3$ fatty acids affect inflammatory processes they might be expected to affect CRP concentrations. Indeed, the concentration of CRP was significantly negatively correlated with the proportion of DHA in the membranes of granulocytes of patients undergoing coronary angiography [59]. Fish oil (3.6 g EPA plus DHA/day for 12 weeks) significantly lowered (by $20 \%$ ) plasma CRP concentrations in patients with rheumatoid arthritis, who have elevated concentrations [60].

\section{$\alpha$-Linolenic acid}

A high dose of $\alpha$-linolenic acid ( $13.7 \mathrm{~g} /$ day for 4 weeks) decreased the production of TNF and IL-1 by human monocytes by an average of 27 and $30 \%$, respectively [13]. The effect of this dose of $\alpha$ linolenic acid compared with reductions of 70 and $78 \%$, respectively, after 4 weeks of $2.7 \mathrm{~g}$ EPA plus $\mathrm{DHA} /$ day [13]. Supplementing the diet of healthy young males with encapsulated linseed oil providing $3.5 \mathrm{~g} \alpha$-linolenic acid /day for 12 weeks did not alter superoxide production by neutrophils or neutrophil chemotaxis [9]. Likewise there was no effect on the production of TNF- $\alpha$, IL-1 $\beta$ and IL6 by monocytes [52]. A similar lack of effect of $\alpha$-linolenic acid ( $2 \mathrm{~g} /$ day for 12 weeks) on production of inflammatory cytokines by monocytes was reported in elderly subjects [45]. There was however, a significant decrease in SVCAM-1 and SE-selectin, but not sICAM-1, concentrations in these subjects [45]. The average decreases were $15 \%$ and $27 \%$, respectively. The decrease in sE-selectin concentration was similar to that seen in subjects consuming $1.1 \mathrm{~g}$ EPA plus DHA/day (23\%; [45]), but the decrease in SVCAM-1 concentration was less than that seen in the subjects consuming long chain n-3 PUFA ( $26 \%$; [45]). A recent intervention study used margarines to provide dietary intakes of 4.5 or $9.5 \mathrm{~g} \alpha$-linolenic acid /day for 6 months, largely at the expense of linoleic acid [18]. There was no effect of $\alpha$-linolenic acid on the ability of neutrophils and monocytes to undergo respiratory burst, or on the production of cytokines (TNF- $\alpha, \mathrm{IL}-1 \beta, \mathrm{IL}-6)$ by mononuclear cells [18]. In another dietary intervention study using margarine and other strategies to provide an average of $6.3 \mathrm{~g} \alpha$ linolenic acid /day for one year, plasma fibrinogen concentration was lower (by approximately $5 \%$ ) 
than in the control group [61]. In another study, $8.1 \mathrm{~g} \alpha$-linolenic acid/day from linseed oil for 12 weeks significantly decreased the serum concentrations of IL-6 (average decrease $23 \%$ ), Creactive protein ( $25 \%$ ) and amyloid $A(26 \%)$ [62]. Thus, a substantial increase in $\alpha$-linolenic acid intake can induce anti-inflammatory effects.

\section{Anti-inflammatory mechanisms of action of dietary $n-3$ fatty acids not involving eicosanoids}

Altered synthesis of eicosanoids is a biologically plausible and readily accepted mechanism by which to explain the actions of certain fatty acids, especially n-3 PUFA upon inflammation. However, many of the effects reported are different from those that would be predicted if EPA was acting as a PGE 2 antagonist. For example, n-3 PUFA decrease production of TNF- $\alpha$ by monocytes and macrophages, but so does $\mathrm{PGE}_{2}$. One explanation for this is that focussing on $\mathrm{PGE}_{2}$ is too simplistic. It may be that it is the overall impact of $n-3$ PUFA on the entire range of arachidonic acid-derived mediators coupled with the increased production of EPA-derived mediators (whose effects are not known and some of which are not yet even discovered) that accounts for the observed effects. Thus, the effects of $n$ 3 PUFA may still be related to eicosanoids. Another explanation is that n-3 PUFA act through eicosanoid-independent mechanisms. These other mechanisms also rely upon an altered fatty acid composition of membrane phospholipids (figure 2) and include effects on the physical nature of the membrane (often referred to as fluidity), the ability of the membrane to undergo structural and functional changes in response to a cellular stimulus, and the ability to generate intracellular signalling molecules. These mechanisms are closely related to one another, since cell membrane composition, fluidity and function and the generation of signalling molecules following a cellular stimulus are interlinked (figure 2) and they are discussed further elsewhere [34]. There is now emerging evidence that $n-6$ and n-3 PUFA regulate the expression of genes involved in inflammation [see 34]. Among the genes that are down-regulated by n-3 PUFA are those encoding TNF- $\alpha$, IL-1, COX-2, 5-LOX, 5-LOX activating protein, certain matrix metalloproteinases, and VCAM1 [see 34 for references]. Since the expression of many of these genes is regulated by the transcription factor nuclear factor kappa $B$ (NFkB), these observations suggest that n-3 PUFA might somehow affect the activity of this transcription factor. This might be through effects on cell signaling leading to NFKB activation. There is recent evidence that dietary fish oil affects NFKB activity [63, 64], in a manner that is consistent with its ability to down-regulate the production of inflammatory mediators.

A second group of transcription factors currently undergoing scrutiny for their role in inflammation are the peroxisome proliferator activated receptors (PPAR). The main members of this family are PPAR $\alpha$ and PPAR $y$. Although PPAR $\alpha$ and $\gamma$ play important roles in liver and adipose tissue, respectively [65], they are also found in inflammatory cells $[66,67]$. PPAR can bind, and appear to be regulated by, PUFA and eicosanoids $[68,69]$. PPAR $\alpha$ deficient mice have a prolonged response to inflammatory stimuli [69], suggesting that PPAR $\alpha$ activation might be anti-inflammatory. More recently activators of both PPAR $\alpha$ and $\gamma$ have been shown to inhibit the activation of a number of inflammatory genes, including TNF- $\alpha$, IL-1 $\beta$, IL-6, IL-8, COX-2 and VCAM-1 [34]. Two mechanisms for the anti-inflammatory actions of PPAR have been proposed [see 70, 71 for reviews]. The first is that PPAR might stimulate the breakdown of inflammatory eicosanoids through induction of peroxisomal $\beta$-oxidation. The second is that PPAR might interfere with or antagonise the activation of other transcription factors, including NFKB. Although the effect of fish oil on PPAR expression in inflammatory cells has not been reported, studies in other tissues [e.g. 72] suggest that $n-3$ PUFA might act by increasing the level of these anti-inflammatory transcription factors in such cells. 


\section{Dietary fatty acids and inflammatory diseases}

Aspirin and non-steroidal anti-inflammatory drugs are widely used for symptom relief in inflammatory disease. These drugs act as COX inhibitors specifically targeting 2-series prostaglandins and thromboxanes. The discovery that long chain n-3 PUFA also act to reduce formation of these mediators promoted studies in animal models and clinical trials in a range of human diseases. Although the mechanistic explanation for the potential benefit of n-3 PUFA is most easily related to their "anti-arachidonic acid" effects, the forgoing discussion strongly suggests that they may act at multiple sites to exert anti-inflammatory effects (figure 3). Dietary fish oil has been shown to increase survival and decrease proteinuria and anti-DNA antibody formation in mice with autoimmune glomerulonephritis (a model of lupus), to decrease joint inflammation in rodent models of arthritis, and to decrease inflammation in rat models of colitis and of type- 1 diabetes [see 32, 33 for references]. N-3 fatty acids can interfere with leukocyte chemotaxis [5, 6, 11, 39-41], adhesion molecule expression [46] and leukocyte-endothelium adhesive interactions [5], the production of chemoattractants (e.g. leukotriene $B_{4}[5,6]$ and monocyte chemotactic peptide 1 [48]), and the production of inflammatory eicosanoids $[5,6,11,13,25]$, cytokines $[11,13,25,47]$, reactive oxygen species $[8,10,42,43]$ and other inflammatory mediators such as platelet activating factor [6].

The efficacy of fish oil has been studied in several inflammatory diseases including rheumatoid arthritis, Crohn's disease, ulcerative colitis, psoriasis, lupus, multiple sclerosis, cystic fibrosis and asthma. Although there are clinical benefits reported from trials in each of these diseases [e.g. see 73-76], the only one for which there is really strong evidence of benefit is rheumatoid arthritis. This may be a reflection of the large number of well designed and well conducted studies in arthritis: there have been at least 14 randomised, placebo-controlled, double-blind studies of fish oil in rheumatoid arthritis. These trials have been reviewed in some detail elsewhere [77-79], and so will be discussed only briefly here. They used between 1 and $7.1 \mathrm{~g}$ EPA plus DHA per day (average dose was $3.3 \mathrm{~g} /$ day) with a duration of 12 to 52 weeks. A variety of improvements in clinical outcome were reported. These include reduced duration of morning stiffness, reduced number of tender or swollen joints, reduced joint pain, reduced time to fatigue, increased grip strength and decreased use of antiinflammatory drugs. It has been concluded that the evidence for benefit from long chain n-3 PUFA in rheumatoid arthritis is robust [80].

There is currently considerable interest in the relative effects of $n-3$ and $n-6$ PUFA in asthma and other atopic diseases [see 81-84 for detailed discussion]. The discussion centers on the roles of various eicosanoids produced from arachidonic acid in mediating allergic inflammation and in programming $T$ lymphocytes to a phenotype that predisposes to such inflammation. Arachidonic acid-derived eicosanoids such as $\mathrm{PGD}_{2}$, and $\mathrm{LTC}_{4}, \mathrm{D}_{4}$ and $\mathrm{E}_{4}$ are produced by the cells that mediate pulmonary inflammation in asthma (e.g. mast cells), and are believed to be the major mediators of asthmatic bronchoconstriction. Thus, it is considered that provision of n-3 PUFA to asthmatics might be beneficial because of the resulting decrease in production of 4-series leukotrienes and other arachidonic acid-derived mediators. However, the situation is complicated by the fact that different eicosanoids have different effects, some antagonising others. For example, the fairly recent observations that $\mathrm{PGE}_{2}$ inhibits 5-LOX [22] and promotes generation of lipoxins that act as inflammation "stop signals" $[23,24]$, indicate that $\mathrm{PGE}_{2}$ could, in fact, be protective in active asthma. Thus, interventions that aim to suppress $\mathrm{PGE}_{2}$ production could be counterproductive, at least in some asthmatics. Nevertheless, a number of trials of fish oil in asthma and related atopic diseases 
have been performed [see 83 for a review]. Most of these studies reveal limited clinical impact, despite significant biochemical changes, although some have shown clinical improvements at least in some patient groups including children [85, 86] and some adults [87]. A recent meta-analysis of fish oil in asthma concluded that there was no evidence of benefit [88], although this analysis did not separate studies in adults and children. However, trying to intervene in the disease once it has developed may be the wrong approach, and n-3 PUFA may still have a role in prevention [see 84]. Since $\mathrm{PGE}_{2}$ regulates $\mathrm{T}$ lymphocyte differentiation promoting the development of the Th2-type phenotype that underlies sensitisation to environmental allergens, it is possible that early exposure to long chain n-3 PUFA may be protective towards allergy, asthma and related diseases. There is some epidemiological evidence in support of this [see 89 for references]. However, despite a biologically plausible mechanism and supportive biochemical and epidemiological data, the key to demonstrating a protective effect of increased long chain n-3 PUFA consumption towards allergictype diseases must come from well-designed placebo-controlled intervention studies. It is now recognised that sensitisation to allergens occurs early in life, and so the characteristics of the maternal diet may be very important in determining predisposition to these diseases. Therefore, studies addressing this question need to be performed early in life and preferably in pregnant women. Several such studies are currently underway and early results from two of them are suggestive of some benefit from early life exposure to long chain n-3 PUFA [90-92]. Evidence of longer-term benefits of such early intervention is awaited.

\section{Conclusions}

The fatty acid composition of human inflammatory cells can be altered by increasing consumption of n-3 PUFA in the diet. This can lead to altered function including decreased generation of reactive oxygen species, arachidonic acid-derived eicosanoids, inflammatory cytokines and adhesion molecules. Thus, when consumed in sufficient quantities n-3 PUFA exert anti-inflammatory effects. However, it is not yet clear what the threshold intake is for these effects to become apparent; this may be different for different aspects of inflammation and may vary with age, gender, genotype, background diet and so on. The effects of long chain n-3 PUFA are greater than those of the shorter chain $\alpha$-linolenic acid. Long chain n-3 PUFA have been demonstrated to be efficacious in the treatment of some inflammatory diseases, especially rheumatoid arthritis. It is possible that long term consumption of $n-3$ PUFA will protect against developing some diseases with an inflammatory component.

\section{REFERENCES}

1. Abbas AK, Lichtman AH, Pober JS (1994). Cellular and Molecular Immunology, Philadelphia, WB Saunders.

2. Ross R (1999). Atherosclerosis - An inflammatory disease. N Eng J Med 340 : 115-26.

3. Plutzky J (1999). Atherosclerotic plaque rupture : emerging insights and opportunities. Am J Cardiol 84 : 15J-20J. 
4. Kew S, Banerjee T, Minihane AM, Finnegan YE, Williams CM, Calder PC (2003). Relation between the fatty acid composition of peripheral blood mononuclear cells and measures of immune cell function in healthy, free-living subjects aged 25-72 y. Am J Clin Nutr 77 : 1278-86.

5. Lee TH, Hoover RL, Williams JD, et al. (1985). Effects of dietary enrichment with eicosapentaenoic acid and docosahexaenoic acid on in vitro neutrophil and monocyte leukotriene generation and neutrophil function. N Eng J Med $312: 1217-24$.

6. Sperling RI, Benincaso Al, Knoell CT, Larkin JK, Austen KF, Robinson DR (1993). Dietary $\omega$ 3 polyunsaturated fatty acids inhibit phosphoinositide formation and chemotaxis in neutrophils. $J$ Clin Invest 91 : 651-60.

7. Gibney MJ, Hunter B (1993). The effects of short- and long-term supplementation with fish oil on the incorporation of $n-3$ polyunsaturated fatty acids into cells of the immune system in healthy volunteers. Eur J Clin Nutr $47: 255-9$.

8. Luostarinen R, Saldeen T (1996). Dietary fish oil decreases superoxide generation by human neutrophils : relation to cyclooxygenase pathway and lysosomal enzyme release. Prost Leuk Essent Fatty Acids 55 : 167-72.

9. Healy DA, Wallace FA, Miles EA, Calder PC, Newsholme P (2000). Effect of low to moderate amounts of dietary fish oil on neutrophil lipid composition and function. Lipids 35 : 763-8.

10. Fisher M, Levine PH, Weiner BH, et al. (1990). Dietary n-3 fatty acid supplementation reduces superoxide production and chemiluminescence in monocyte enriched preparation of leukocytes. $\mathrm{Am}$ J Clin Nutr $51: 804-8$.

11. Endres S, Ghorbani R, Kelley VE, et al. (1989) The effect of dietary supplementation with n3 polyunsaturated fatty acids on the synthesis of interleukin-1 and tumor necrosis factor by mononuclear cells. N Eng J Med 320 : 265-71.

12. Molvig J, Pociot F, Worsaae H, et al. (1991) Dietary supplementation with omega 3 polyunsaturated fatty acids decreases mononuclear cell proliferation and interleukin 1 beta content but not monokine secretion in healthy and insulin dependent diabetic individuals. Scand J Immunol 34 : 399-410.

13. Caughey GE, Mantzioris E, Gibson RA, Cleland LG, James MJ (1996). The effect on human tumor necrosis factor $\alpha$ and interleukin $1 \beta$ production of diets enriched in $n-3$ fatty acids from vegetable oil or fish oil. Am J Clin Nutr $63: 116-22$.

14. Yaqoob P, Pala HS, Cortina-Borja M, Newsholme EA, Calder PC (2000). Encapsulated fish oil enriched in $\alpha$-tocopherol alters plasma phospholipid and mononuclear cell fatty acid compositions but not mononuclear cell functions. Eur J Clin Invest $30: 260-74$.

15. Thies F, Nebe-von-Caron G, Powell JR, Yaqoob P, Newsholme EA, Calder PC (2001). Dietary supplementation with gamma linolenic acid or fish oil decreases T lymphocyte proliferation in healthy older humans. J Nutr $131 ; 1918-27$. 
16. Kelley DS, Nelson GJ, Love JE, et al. (1993). Dietary $\alpha$-linolenic acid alters tissue fatty acid composition, but not blood lipids, lipoproteins or coagulation status in humans. Lipids 28 : 533-7.

17. Mantzioris E, James MJ, Gibson RA, Cleland LG (1994). Dietary substitution with an $\alpha$-linolenic acid-rich vegetable oil increases eicosapentaenoic acid concentrations in tissues. Am J Clin Nutr 59 : 1304-9.

18. Kew S, Banerjee T, Minihane AM, et al. (2003). Lack of effect of foods enriched with plant- or marine-derived n-3 fatty acids on human immune function. Am J Clin Nutr 77 : 1287-95.

19. Goldyne ME, Stobo JD (1982). Human monocytes synthesize eicosanoids from T lymphocytederived arachidonic acid. Prostaglandins 24 : 623-30.

20. Lewis RA, Austen KF, Soberman RJ (1990). Leukotrienes and other products of the 5-lipoxygenase pathway : biochemistry and relation to pathobiology in human diseases. N Eng J Med 323 : 645-55.

21. Tilley SL, Coffman TM, Koller BH (2001). Mixed messages : modulation of inflammation and immune responses by prostaglandins and thromboxanes. J Clin Invest $108: 15-23$.

22. Levy BD, Clish CB, Schmidt B, Gronert K, Serhan CN (2001). Lipid mediator class switching during acute inflammation : signals in resolution. Nature Immunol 2 : 612-9.

23. Gewirtz AT, Collier-Hyams LS, Young AN, et al. (2002). Lipoxin A4 analogs attenuate induction of intestinal epithelial proinflammatory gene expression and reduce the severity of dextran sodium sulfate-induced colitis. J Immunol 168 : 5260-7.

24. Vachier I, Chanez P, Bonnans C, Godard P, Bousquet J, Chavis C (2002). Endogenous antiinflammatory mediators from arachidonate in human neutrophils. Biochem Biophys Res Commun $290: 219-24$.

25. Meydani SN, Endres S, Woods MM, et al. (1991). Oral (n-3) fatty acid supplementation suppresses cytokine production and lymphocyte proliferation : comparison between young and older women. J Nutr 121 : 547-55.

26. Obata T, Nagakura T, Masaki T, Maekawa K, Yamashita K (1999). Eicosapentaenoic acid inhibits prostaglandin D2 generation by inhibiting cyclo-oxygenase-2 in cultured human mast cells. Clin Exp Allergy 29 : 1129-35.

27. Curtis CL, Hughes CE, Flannery CR, Little CB, Harwood JL, Caterson B (2000). N-3 fatty acids specifically modulate catabolic factors involved in articular cartilage degradation. J Biol Chem 275 : 721-4.

28. Curtis CL, Rees SG, Little CB, et al. (2002). Pathologic indicators of degradation and inflammation in human osteoarthritic cartilage are abrogated by exposure to n-3 fatty acids. Arth Rheum $46: 1544-$ 53.

29. Miles EA, Allen E, Calder PC (2002). In vitro effects of eicosanoids derived from different 20carbon fatty acids on production of monocyte-derived cytokines in human whole blood cultures. Cytokine $20: 215-23$. 
30. Miles EA, Aston L, Calder PC (2003). In vitro effects of eicosanoids derived from different 20carbon fatty acids on T helper type 1 and T helper type 2 cytokine production in human whole-blood cultures. Clin Exp Allergy 33 : 624-32.

31. Serhan CN, Clish CB, Brannon J, Colgan SP, Gronert K, Chiang N (2000). Anti-inflammatory lipid signals generated from dietary $n-3$ fatty acids via cyclooxygenase-2 and transcellular processing : a novel mechanism for NSAID and n-3 PUFA therapeutic actions. J Physiol Pharmacol 4 : 643-54.

32. Calder PC (1997). N-3 polyunsaturated fatty acids and cytokine production in health and disease. Ann Nutr Metab 41 : 203-34.

33. Calder PC (2001). Polyunsaturated fatty acids, inflammation and immunity. Lipids 36 : 1007-24.

34. Calder PC (2002). Dietary modification of inflammation with lipids. Proc Nutr Soc 61 : 345-58.

35. Calder PC (2003). N-3 polyunsaturated fatty acids and inflammation : from molecular biology to the clinic. Lipids $38: 342-52$.

36. Calder PC, Yaqoob P, Thies F, Wallace FA, Miles EA (2002). Fatty acids and lymphocyte functions. Brit J Nutr 87 : S31-S48.

37. Yaqoob $P$ (2003). Lipids and the immune response : from molecular mechanisms to clinical applications. Curr Opin Clin Nutr Metab Care 6 : 133-50.

38. Calder PC (2001). N-3 polyunsaturated fatty acids, inflammation and immunity : pouring oil on troubled waters or another fishy tale ? Nutr Res $21: 309-41$.

39. Schmidt EB, Pedersen JO, Ekelund S, Grunnet N, Jersild C, Dyerberg J (1989). Cod liver oil inhibits neutrophil and monocyte chemotaxis in healthy males. Atheroslerosis 77 : 53-7.

40. Schmidt EB, Varming K, Pedersen JO, et al. (1992). Long term supplementation with $\mathrm{n}-3$ fatty acids. ii. effect on neutrophil and monocyte chemotaxis. Scand J Clin Lab Invest 52 : 229-36.

41. Luostarinen R, Siegbahn A, Saldeen T (1992). Effect of dietary fish oil supplemented with different doses of vitamin E on neutrophil chemotaxis in healthy volunteers. Nutr Res $12: 1419-30$.

42. Thompson PJ, Misso NLA, Passarelli M, Phillips MJ (1991). The effect of eicosapentaenoic acid consumption on human neutrophil chemiluminescence. Lipids 26 : 1223-6.

43. Varming K, Schmidt EB, Svaneborg N, et al. (1995). The effect of $\mathrm{n} 3$ fatty acids on neutrophil chemiluminescence. Scand J Clin Lab Invest 55 : 47-52.

44. Schmidt EB, Varming K, Moller JM, Bulow Pederson I, Madsen P, Dyerberg J (1996). No effect of a very low dose of $n-3$ fatty acids on monocyte function in healthy humans. Scand J Clin Invest $56: 87-$ 92.

45. Thies F, Miles EA, Nebe-von-Caron G, et al. (2001). Influence of dietary supplementation with long-chain $n-3$ or $n-6$ polyunsaturated fatty acids on blood inflammatory cell populations and functions and on plasma soluble adhesion molecules in healthy humans. Lipids $36: 1183-93$. 
46. Hughes DA, Pinder AC, Piper Z, Johnson IT, Lund EK (1996). Fish oil supplementation inhibits the expression of major histocompatibility complex class II molecules and adhesion molecules on human monocytes. Am J Clin Nutr 63 : 267-72.

47. Meydani SN, Lichtenstein AH, Cornwall S, et al. (1993). Immunologic effects of National Cholesterol Education Panel Step-2 Diets with and without fish-derived n-3 fatty acid enrichement. J Clin Invest 92 : 105-13.

48. Baumann KH, Hessel F, Larass I, Muller T, Angerer P, Kiefl R, von Schacky C (1999). Dietary $\omega-3, \omega-$ 6 , and $\omega-9$ unsaturated fatty acids and growth factor and cytokine gene expression in unstimulated and stimulated monocytes. Arterioscler Thromb Vasc Biol 19 : 59-66.

49. Wallace JMW, Turley E, Gilmore WS, Strain JJ (1995). Dietary fish oil supplementation alters leukocyte function and cytokine production in healthy women. Arterioscler Thromb Vasc Biol 15 : 185-9.

50. Cooper AL, Gibbons L, Horan MA, Little RA, Rothwell NJ (1993). Effect of dietary fish oil supplementation on fever and cytokine production in human volunteers. Clin Nutr 12 : 321-8.

51. Blok WL, Deslypere J-P, Demacker PNM, et al. (1997). Pro- and anti-inflammatory cytokines in healthy volunteers fed various doses of fish oil for 1 year. Eur J Clin Invest 27 : 1003-8.

52. Wallace FA, Miles EA, Calder PC (2003). Comparison of the effects of linseed oil and different doses of fish oil on mononuclear cell function in healthy subjects. Brit J Nutr 89 : 679-89.

53. Grimble RF, Howell WM, O'Reilly G, et al. (2002). The ability of fish oil to suppress tumor necrosis factor- $\alpha$ production by peripheral blood mononuclear cells in healthy men is associated with polymorphisms in genes that influence tumor necrosis factor $\alpha$ production. Am J Clin Nutr 76 : 454-9.

54. Yli-Jama P, Seljeflot I, Meyer HE, Hjerkinn EM, Arnesen H, Pedersen JI (2002). Serum nonesterified very long-chain PUFA are associated with markers of endothelial dysfunction. Atherosclerosis $164: 275-81$.

55. Miles EA, Thies F, Wallace FA, et al. (2001). Influence of age and dietary fish oil on plasma soluble adhesion molecule concentrations. Clin Sci 100 : 91-100.

56. Seljeflot I, Arnesen H, Brude IR, Nenseter MS, Drevon CA, Hjermann I (1998). Effects of omega3 fatty acids and/or antioxidants on endothelial cell markers. Eur J Clin Invest $28: 629-35$.

57. Abe Y, El-Masri B, Kimball KT, et al. (1998). Soluble adhesion molecules in hypertriglyceridaemia and potential significance on monocyte adhesion. Arterioscler Thromb Vasc Biol 18 : 723-31.

58. Johansen O, Seljeflot I, Hostmark AT, Arnesen H (1999). The effect of supplementation with omega-3 fatty acids on soluble markers of endothelial function in patients with coronary heart disease. Arterioscler Thromb Vasc Biol 19 : 1681-6.

59. Madsen T, Skou HA, Hansen VE, et al. (2001). C-reactive protein, dietary n-3 fatty acids, and the extent of coronary artery disease. Am J Cardiol 88 : 1139-42. 
60. Nielsen GL, Faarvang KL, Thomsen BS, et al. (1992). The effects of dietary supplementation with n-3 polyunsaturated fatty acids in patients with rheumatoid arthritis : a randomized, double blind trial. Eur J Clin Invest 22 : 687-91.

61. Bemelmans WJ, Broer J, Feskens EJ, et al. (2002). Effect of increased intake of alpha-linolenic acid and group nutritional education on cardiovascular risk factors : the Mediterranean Alpha-linolenic Enriched Groningen Dietary Intervention (MARGARIN). Am J Clin Nutr 75 : 221-7.

62. Rallidis LS, Paschos G, Liakos GK, Velissaridou AH, Anastasiadis G, Zampelas A (2003). Dietary $\alpha$ linolenic acid decreases $C$-reactive protein, serum amyloid $A$ and interkeukin- 6 in dyslipidaemic patients. Atherosclerosis $167:$ 237-42.

63. Lo CJ, Chiu KC, Fu MJ, Chu A, Helton S (2000). Fish oil modulates macrophage P44/42 mitogenactivated protein kinase activity induced by lipopolysaccharide. J Parent Ent Nut 24 : 159-63.

64. Xi S, Cohen D, Barve S, Chen LH (2001). Fish oil suppressed cytokines and nuclear factor kappaB induced by murine AIDS virus infection. Nutr Res $21: 865-78$.

65. Schoonjans K, Staels B, Auwerx J (1996). The peroxisome proliferator activated receptors (PPARs) and their effects on lipid metabolism and adipocyte differentiation. Biochim Biophys Acta 1302 : 93109.

66. Chinetti G, Griglio S, Antonucci M, et al. (1998). Activation of peroxisome-activated receptors alpha and gamma induces apoptosis of human monocyte-derived macrophages. J Biol Chem 273 : 25573-80.

67. Ricote M, Li AC, Willson TM, Kelly CJ, Glass CK (1998). The peroxisome proliferator-activated receptor-gamma is a negative regulator of macrophage activation. Nature $391:$ 79-82.

68. Kleiwer SA, Lenhard JM, Willson TM, Patel I, Morris DC, Lehman JM (1995). A prostaglandin J2 metabolite binds peroxisome proliferator-activated receptor $\gamma$ and promotes adipocyte differentiation. Cell $83: 813-9$.

69. Devchand PR, Keller H, Peters JM, Vazquez M, Gonzalez FJ, Wahli W (1996). The PPAR $\alpha$ leukotriene $\mathrm{B}_{4}$ pathway to inflammation control. Nature 384 : 39-43.

70. Chinetti G, Fruchart JC, Staels B (2000). Peroxisome proliferator-activated receptors (PPARs) : nuclear receptors at the crossroads between lipid metabolism and inflammation. Inflamm Res 49 : 497-505.

71. Delerive P, Fruchart JC, Staels B (2001). Peroxisome proliferator-activated receptors in inflammation control. J Endocrinol 169 : 453-9.

72. Berthou L, Saladin R, Yaqoob P, et al. (1995). Regulation of rat liver apolipoprotein A-I, apolipoprotein A-II and acyl CoA oxidase gene expression by fibrates and dietary fatty acids. Eur $\mathrm{J}$ Biochem 232 : 179-87.

73. Belluzi A, Miglio F (1998). N-3 fatty acids in the treatment of Crohn's disease. In : Kremer JM, Medicinal Fatty Acids in Inflammation. Basel, Birkhauser, pp. 91-101. 
74. Rodgers JB (1998). N -3 fatty acids in the treatment of ulcerative colitis. In : Kremer JM, Medicinal Fatty Acids in Inflammation. Basel, Birkhauser, pp. 103-9.

75. Ziboh VA (1998). The role of n-3 fatty acids in psoriasis. In : Kremer JM, Medicinal Fatty Acids in Inflammation. Basel, Birkhauser, pp. 45-53.

76. Beckles Willson N, Elliott TM, Everard ML (2003). Omega-3 fatty acids (from fish oils) for cystic fibrosis (Cochrane Review). In : The Cochrane Library, Issue 2, Oxford, Update Software.

77. Geusens PP (1998). N-3 fatty acids in the treatment of rheumatoid arthritis. In : Kremer JM, Medicinal Fatty Acids in Inflammation. Basel, Birkhauser, pp. 111-23.

78. Calder PC (2001). N-3 fatty acids and rheumatoid arthritis. In : Ransley JK, Donnelly JK, Read NW, Food and Nutritional Supplements in Health and Disease. London, Springer Verlag, pp. 175-97.

79. Calder PC, Zurier RB (2001). Polyunsaturated fatty acids and rheumatoid arthritis. Curr Opin Clin Nutr Metab Care 4 : 115-21.

80. Cleland LG, James MJ (2000). Fish oil and rheumatoid arthritis : antiinflammatory and collateral health benefits. J Rheumatol 27 : 2305-7.

81. Hodge L, Peat JK, Salome C (1994). Increased consumption of polyunsaturated oils may be a cause of increased prevalence of childhood asthma. Aust NZ J Med $24: 727$.

82. Black PN, Sharp S (1997). Dietary fat and asthma : is there a connection ? Eur Resp J 10 : 6-12.

83. Calder PC, Miles EA (2000). Fatty acids and atopic disease. Pediat All Immunol 11 (Suppl.) : 29-36.

84. Prescott SL, Calder PC (2004). N-3 polyunsaturated fatty acids and allergic disease. Curr Opin Clin Nutr Metab Care, 7 : 123-29.

85. Hodge L, Salome CM, Peat JK, Haby MM, Xuan W, Woolcock AJ (1996). Consumption of oily fish and childhood asthma risk. Med J Aust 164 : 137-40.

86. Nagakura T, Matsuda S, Shichijyo K, Sugimoto H, Hata K (2000). Dietary supplementation with fish oil rich in omega-3 polyunsaturated fatty acids in children with bronchial asthma. Eur Resp J 16 : 8615 .

87. Broughton KS, Johnson CS, Pace BK, Liebman M, Kleppinger KM (1997). Reduced asthma symptoms with n-3 fatty acid ingestion are related to 5-series leukotriene production. Am J Clin Nutr $65: 1011-7$.

88. Woods RK, Thien FCK, Abramson MJ (2003). Dietary marine fatty acids (fish oil) for asthma in adults and children. In : The Cochrane Library, Issue 2, Oxford, Update Software.

89. Calder PC (2003). Polyunsaturated fatty acids and cytokine profiles : a clue to the changing prevalence of atopy ? Clin Exp Allergy 33 : 412-5.

90. Mihrshahi S, Peat JK, Marks GB, et al. (2003). Eighteen-month outcomes of house dust mite avoidance and dietary fatty acid modification in the Childhood Asthma Prevention Study (CAPS). J All Clin Immunol $111: 162-8$. 
91. Dunstan JA, Mori TA, Barden A, et al. (2003). Maternal fish oil supplementation in pregnancy reduces interleukin-13 levels in cord blood of infants at high risk of atopy. Clin Exp Allergy 33 : 442-8.

92. Dunstan J, Mori TA, Barden A, et al. (2003). Fish oil supplementation in pregnancy modifies neonatal allergen-specific immune responses and clinical outcomes in infants at high risk of atopy : a randomised controlled trial. J All Clin Immunol, 112 : 1178-84.n

Illustrations

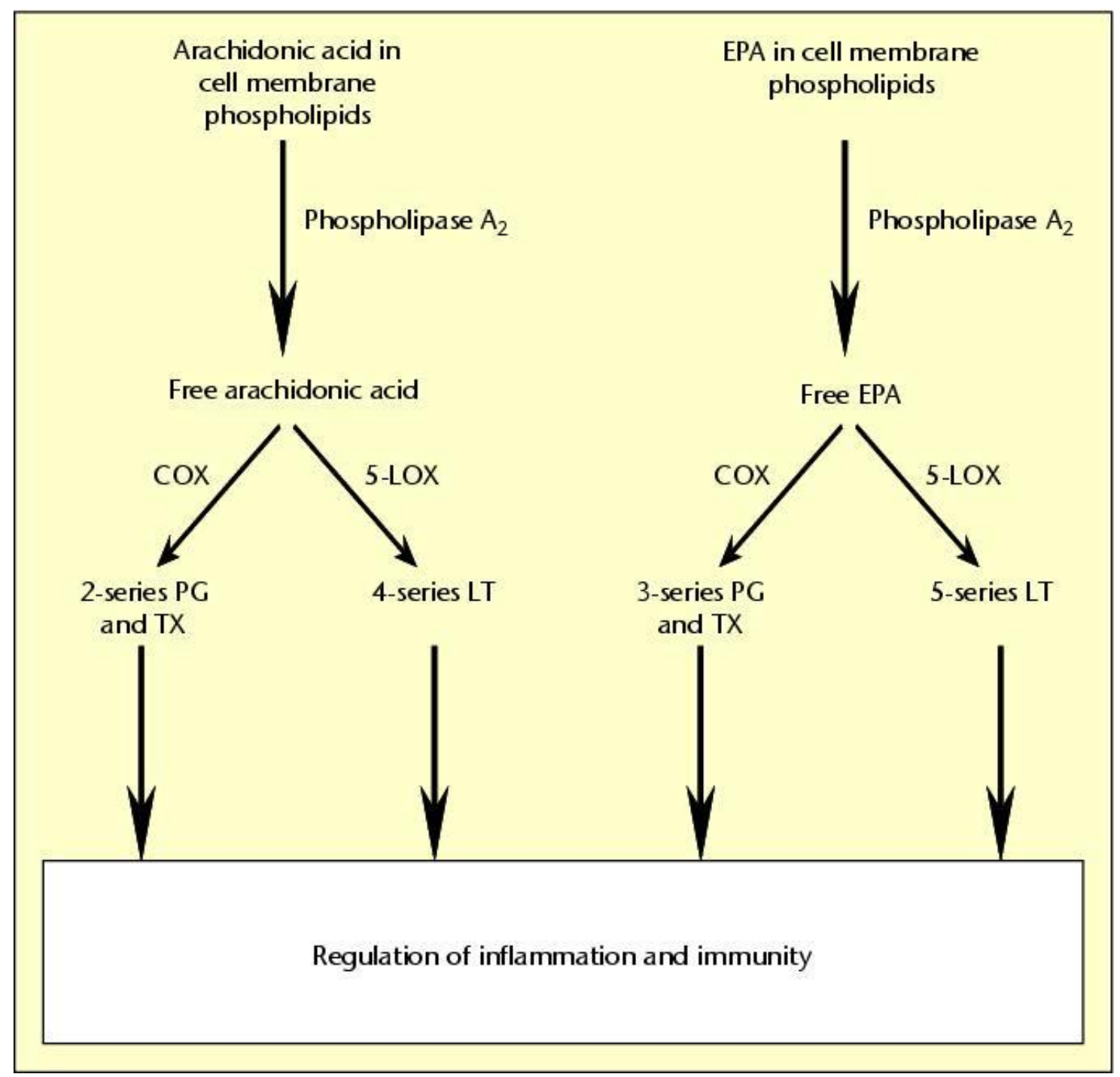

Figure 1. Metabolism of 20 carbon polyunsaturated fatty acids to yield eicosanoids. COX, cyclooxygenase ; EPA, eicosapentaenoc acid ; LOX, lipoxygenase ; $L T$, leukotrienes ; PG, prostaglandins; $T X$, thromboxanes. 


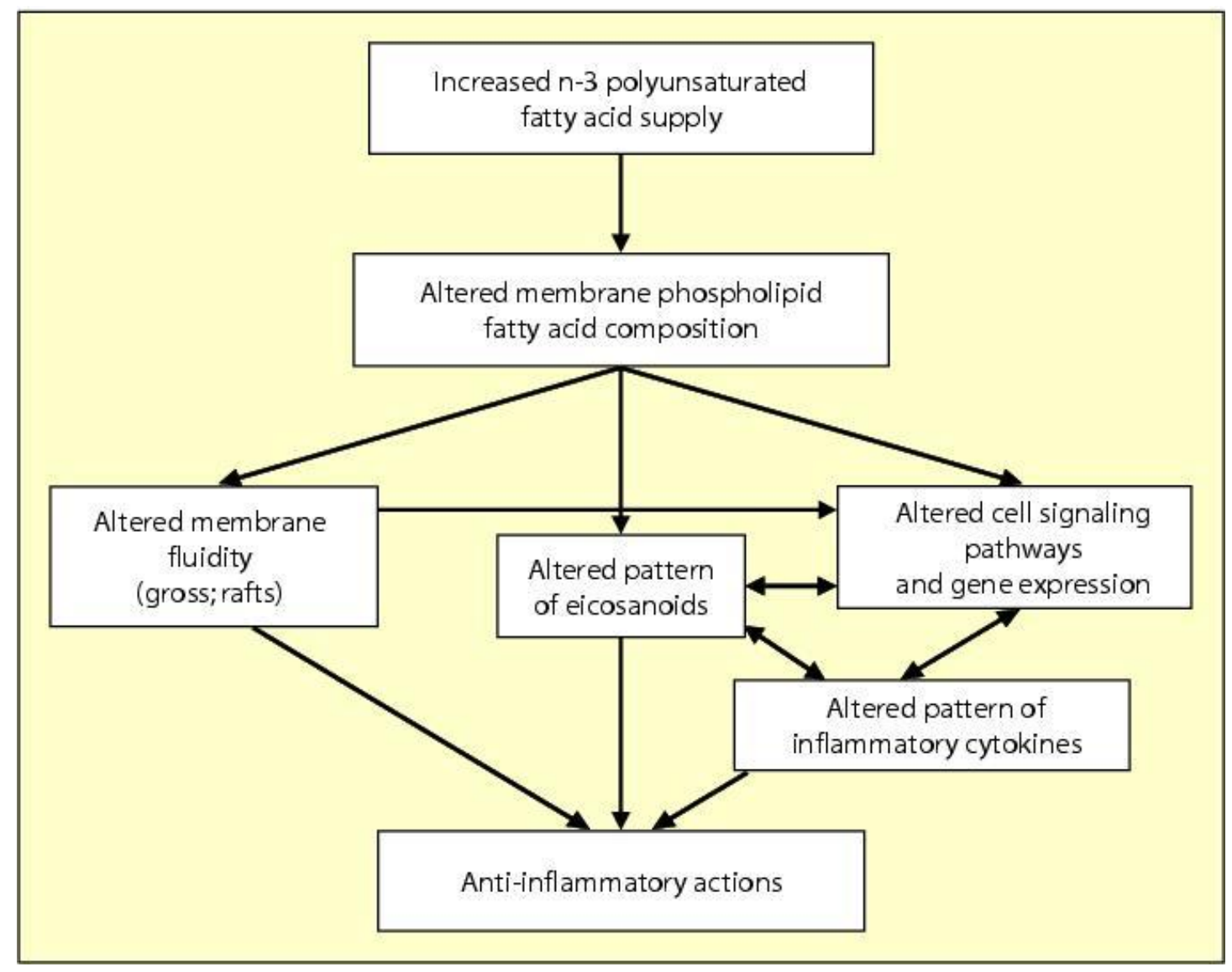

Figure 2. Potential mechanisms by which $n-3$ fatty acids can affect inflammatory cell function.

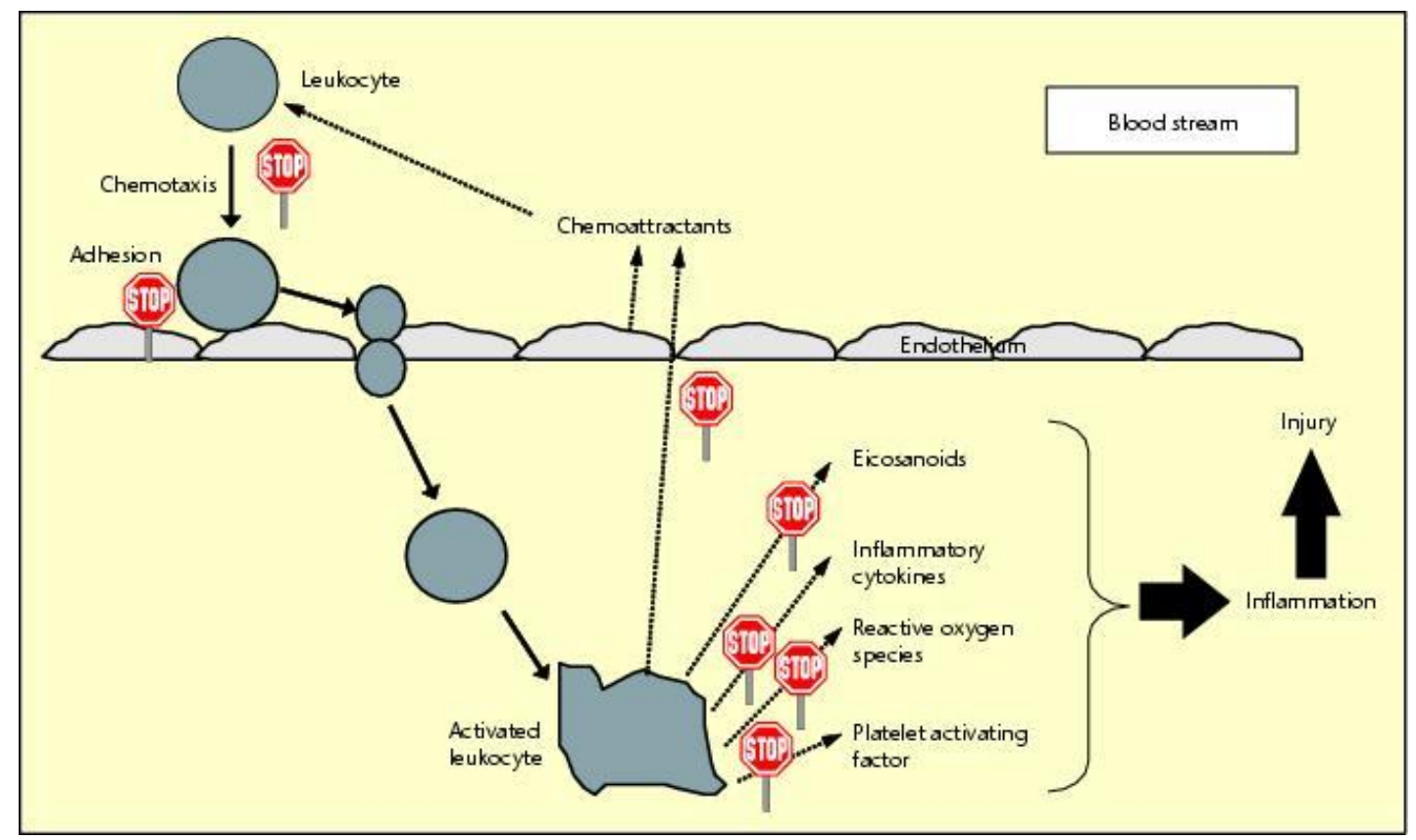

Figure 3. Multiple sites of anti-inflammatory action of $n-3$ fatty acids. 